ARISTOTELES

KATEGORIEN 


\title{
ARISTOTELES WERKE
}

IN DEUTSCHER ÜBERSETZUNG

\author{
BEGRUNDET VON \\ ERNST GRUMACH \\ HERAUSGEGEBEN VON \\ HELLMUT FLASHAR
}

BAND 1

TEIL I

KATEGORIEN

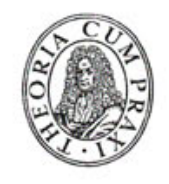

AKADEMIE-VERLAG - BERLIN 


\title{
ARISTOTELES
}

\section{KATEGORIEN}

\author{
UBERSETZT UND ERLÄUTERT VON
}

KLAUS OEHLER

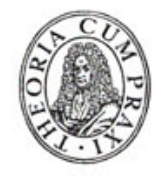

AKADEMIE-VERLAG - BERLIN 
Erschienen im Akademie-Verlag, DDR - 1086 Berlin, Leipziger Str. 3-4

(c) Akademie-Verlag Berlin 1984

Lizenznummer : $202 \cdot 100 / 242 / 84$

Printed in the German Democratic Republic

Gesamtherstellung: IV/2/14 VEB Druckerei "Gottfried Wilhelm Leibniz", 4450 Gräfenhainichen $\cdot 6106$

LSV 0116

Bestellnummer: $7542499 \cdot 3022 / \mathrm{I} / 1$ 